\title{
Activity-Dependent Short-Term Enhancement of Intercellular Coupling
}

\author{
Alberto E. Pereda and Donald S. Faber \\ Department of Anatomy and Neurobiology, Medical College of Pennsylvania and Hahnemann University, \\ Philadelphia, Pennsylvania 19129
}

It was reported previously that repeated brief tetanization of the posterior eighth nerve can produce long-term homosynaptic potentiations of the electrotonic and chemical components of the mixed EPSP evoked in the Mauthner cell lateral dendrite by a single stimulus to the nerve. We show here that the same stimulus paradigm can lead, alternatively, to short-term enhancements of both excitatory responses. These transient modifications last for $\sim 3 \mathrm{~min}$, with a time course similar to post-tetanic potentiation at chemical synapses. However, a different stimulus pattern that transiently increases the presynaptic calcium concentration, paired-nerve stimuli, does not have any significant effect on electrotonic transmission, whereas it facilitates the chemically mediated EPSP. On the other hand, induction of the short-lasting potentiation of coupling, which depended on the discontinuous or burst-like prop- erty of the tetanizing paradigm, required NMDA-receptor activation and was blocked by postsynaptic intradendritic injections of the calcium chelator bis(2-aminophenoxy)ethane$N, N, N^{\prime}, N^{\prime}$-tetra-acetic acid. The ineffectiveness of presynaptic calcium in potentiating electrotonic coupling likely reflects the involvement of a calcium-dependent regulatory protein in the postsynaptic cell and suggests that hemichannels on the two sides of a gap junction plaque can be modified independently. NMDA-mediated modulation of gap junctions could be widespread, because both types of channels coexist during development and in several mammalian adult central nervous system structures such as hippocampus.

Key words: gap junctions; NMDA; calcium; glutamate; Mauthner cell; electrical synapses; activity-dependent plasticity
There exist two basic forms of synaptic transmission: chemical, which is the most common modality among vertebrates and, therefore, is studied more extensively, and electrical or electrotonic. Whereas chemical transmission involves a complex sequence of events, including the presynaptic release of a transmitter substance and its interaction with specific postsynaptic receptors, electrotonic transmission typically is mediated by transcellular current flow through clusters of intercellular channels, or gap junctions (Bennett, 1977). These channels couple neighboring cells electrically and biochemically by providing a low-resistance pathway for the spread of electrical currents and access for the diffusion of small metabolites (Bennett and Spray, 1987; Bennett et al., 1991). Although it is accepted universally that the strength of chemical synapses can undergo a variety of short- or long-term changes (Jessel and Kandel, 1995), it has been assumed that electrotonic synapses are less modifiable, probably because of the relative simplicity of the coupling mechanism.

Several observations suggest that in the central nervous system (CNS) both the presence and the degree of intercellular coupling via gap junctions are subject to dynamic controls. For example, the regulation of electrical coupling is believed to play an important role during development and in the adult brain. Coupling via gap junctions is more widespread before and during the period

Received Aug. 18, 1995; revised (Oct. 20, 1945; accepted Oct. $25,1945$.

This work was supported in part by National Institutes of Health Grant NS15335. We thank M. Volaski for software design and computer support, and we thank Drs. K. Engish, R. Waldeck, P. Castillo, and M. Pinter for critically reading this manuscript.

Correspondence should be addressed to Alberto E. Pereda. Department of Anatomy and Neurobiology, Medical College of Pennsylvania and Hahnemann University, 3200 Henry Avenuc, Philadelphia, PA $1912 \%$.

Copyright 01996 Society for Neuroscience $027(1-6474 / 96 / 160983-10 \$ 05.00 / 0$ when synapses and neural circuits are formed, decreasing as differentiation proceeds (Kandler and Katz, 1993; Peinado et al., 1993; Penn et al., 1994). Furthermore, in the adult vertebrate brain the degree of electrical and dye coupling is modulated by the action of neurotransmitters or modulators. Possibly the best characterized example is dopamine, which modulates cell coupling in the vertebrate retina ('Teranishi, 1983; Piccolino ct al., 1987), nucleus accumbens (O'Donnell and Grace, 1993), striatum (Cepeda et al., 1989), medulla (Pereda et al., 1992, 1994), and in the invertebrate stomatogastric ganglion (Johnson et al., 1993). With the exception of the well characterized retinal horizontal cell system, the functional role and the mechanisms of the dynamic properties of intercellular coupling in the CNS still remain obscure, primarily because of disadvantageous experimental conditions.

Numerous characteristics make one of primary afferents to the goldfish Mauthner (M) cell, namely, the "large myelinated club endings" (LMCE) of posterior eighth-ncrve fibers (Bartelmez, 1915; Bodian, 1937), an ideal system for studying dynamic aspects of electrotonic transmission. First, electrical transmission can be reliably evoked and measured. The parent axons of these afferents, which originate in the sacculus, send only one branch each to the distal part of the lateral dendrite of the $M$ cell, and the endings have electrotonic and chemical junctions with the dendrite (Nakajima, 1974; Tuttle et al., 1986; Lin and Faber, I988a). Electrical stimulation of the posterior eighth nerve produces a biphasic excitatory response consisting of a fast clcctrotonic component, or coupling potential, followed by a chemical glutamatergic EPSP (Furshpan, 1964; Lin and Faber, 1988a; Wolszon and Faber, 1988). Given the brief membrane time constant of the $M$ cell $(\sim 400 \mu \mathrm{sec})$ (Fukami ct al., 1964), these responses can be clearly 

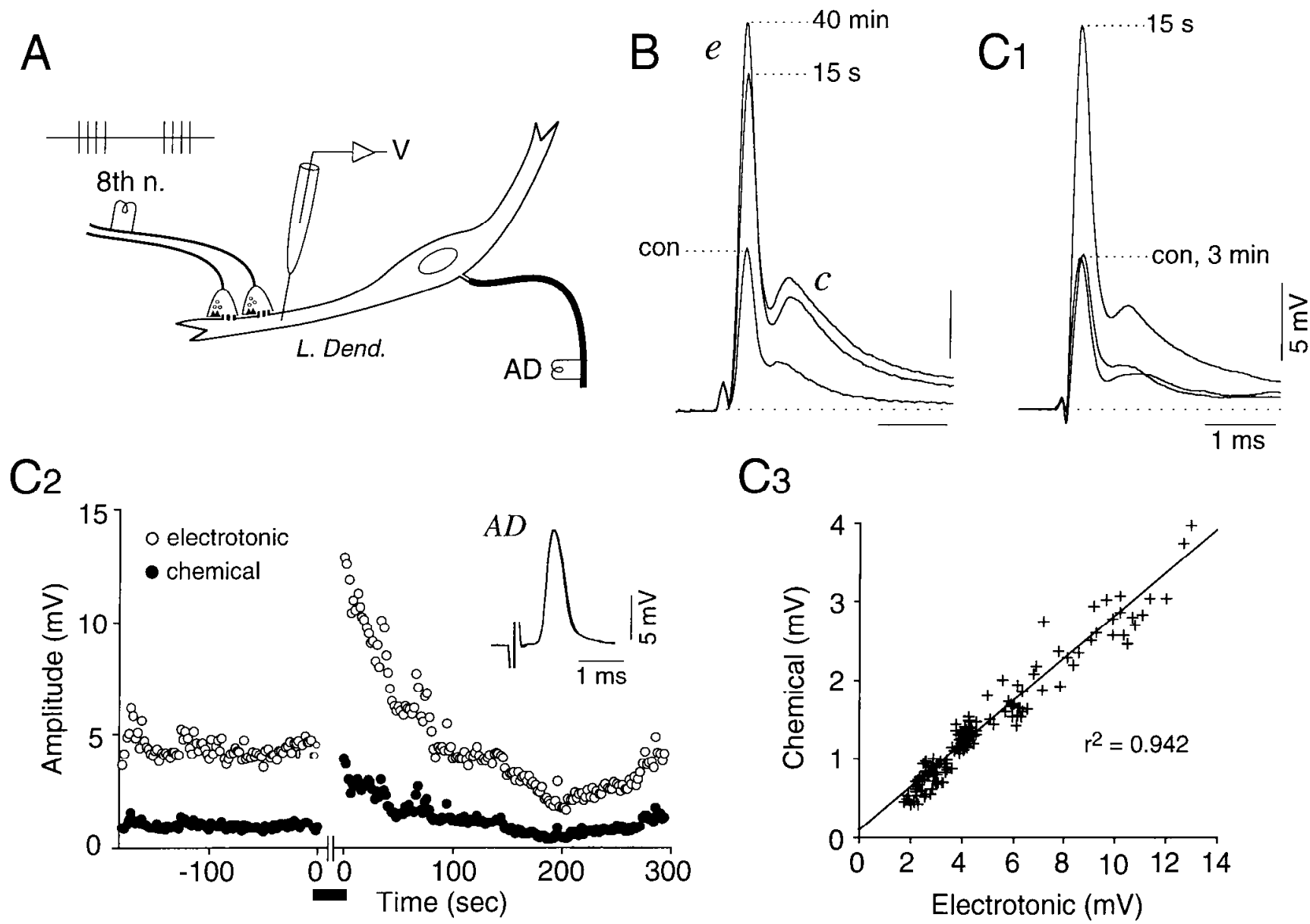

$\mathrm{C}_{3}$

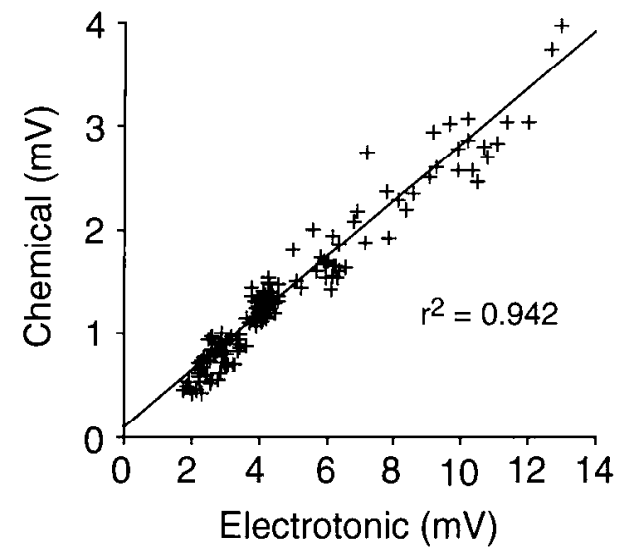

Figure 1. Discontinuous tetanic stimulation can lead to either long- or short-lasting potentiations of the eighth nerve-evoked synaptic response. $A$, Experimental arrangement. The responses elicited by stimulating in the posterior eighth nerve $(8 t h n$.) or the spinal cord $(A D)$ were recorded intracellularly $(V)$ at the distal part of the lateral dendrite of the $\mathrm{M}$ cell $(L$. Dend.). Stimulation of the posterior eighth nerve evokes a mixed synaptic response consisting of a fast elcctrotonic potential $(B, e)$ followed by a chemical EPSP $(B, c) . B, C$, Results from two separate experiments showing that discontinuous tetanic stimulation of this input (detail in Materials and Methods) produces an early ( $B$, con vs $15 \mathrm{~s}$; $C 1$, con vs $15 \mathrm{~s}$ ) potentiation of both components of this response, which is either long $(B, 10 \mathrm{~min})$ or short $(C 1,3 \mathrm{~min})$ lasting. Superimposed traces in $B$ and $C 1$ represent averages of 15 or more consecutive responses. $C 2$, Plot of the amplitudes of both the electrotonic $(O)$ and the chemical (O) components of the synaptic responses against time for the experiment in C1. Horizontal bars in this and subsequent figures represent the period of tetanic stimulation. Inset, Superimposed averaged AD spikes $(A D)$ obtained before and immediately after high-frequency stimulation of the posterior eighth nerve. $C 3$, These transient changes also wcre correlated temporally. Plot of the amplitude of the chemical EPSP ( $y$-axis) versus that of the electrotonic component ( $x$-axis) of the same synaptic responses, obtained during the first $3 \mathrm{~min}$ after tetanic stimulation. During recovery from potentiation, the response amplitudes were related in a linear manner (EPSPs $=0.08 \mathrm{mV}+0.27\left(\right.$ Coup); $\left.r^{2}=0.942\right)$

individualized and quantified. Second, the role of the electrical coupling can be related to a specific cellular function, namely, the fast synaptic transfer of sensory information from the periphery, matching the requirement of the startle reflex mediated by the $M$ cell (Eaton et al., 1991) for speed. Finally, junctional conductance at these terminals can be moditied by homosynaptic afferent activity (Yang et al., 1990); Yang and Faber, 1991), dopamine (Pereda et al., 1992, 1994), and changes in membrane potential of the afferent fiber (Pereda et al., 1995).

We show here that electrotonic synapses at LMCEs also exhibit activity-dependent short-term plasticity, a feature that so far has been reported only for chemical synapses. The results indicate that these short-term changes in electrotonic synapses require an increase in postsynaptic concentration of calcium that is mediated via activation of postsynaptic NMDA receptors.

\section{MATERIALS AND METHODS}

Recordings werc obtained from left $M$ cells of 56 goldfish (Carassius auratus) perfused through the mouth with cold tap water and immobilized with $d$-tubocurarine injected intramuscularly (1-3 $\mathrm{mg} / \mathrm{gm}$ body weight). In all experiments, standard surgical procedures were used as described previously (Faber and Korn, 1978); intracellular recordings were obtained in vivo from the lateral dendrite -300 to $350 \mu \mathrm{m}$ from the soma of the $\mathrm{M}$ cell, either with a potassium acetate $(4 \mathrm{M})$-containing or a potassium chloride $(2.5 \mathrm{M})$-containing electrode of 6 to $16 \mathrm{M} \Omega$ resistance. In one set of experiments, the calcium chelator bis(2-aminophenoxy)ethane$N, N, N^{\prime}, N^{\prime}$-tetra-acetic acid (BAPTA, tetrapotassium salt; Sigma, St.

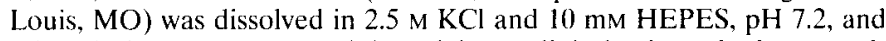
this solution was pressure-injected intracellularly through the recording electrode by positive pressure and iontophoresis. In another set, a combination of two specific NMDA-receptor blockers, DL-2-amino-5phosphonovaleric acid (APV; Sigma) and bis(2-carboxypiperazine4-yl)propyl-1-phosphonic acid (CPP, Research Biochemicals, Natick, MA), was applied by superfusion ( $50-100 \mu \mathrm{M}$ each in saline). The composite monosynaptic synaptic responses were obtained by low-strength stimulation of the posterior branch of the ipsilateral eighth nerve (Fig. $1 A I$ ). Stimulation intensity was such that the range of response amplitudes was $8-10 \mathrm{mV}$ for the electrotonic coupling potential (Fig. $1 B, e$ ) and $3-5 \mathrm{mV}$ for the chemical EPSP (Fig. $1 B, c$ ). Even the largest electrotonic PSPs were subthreshold for orthodromic spike initiation at the initial segment of the axon, presumably because of attenuation along the dendrite (Faber and Korn, 1978). During 

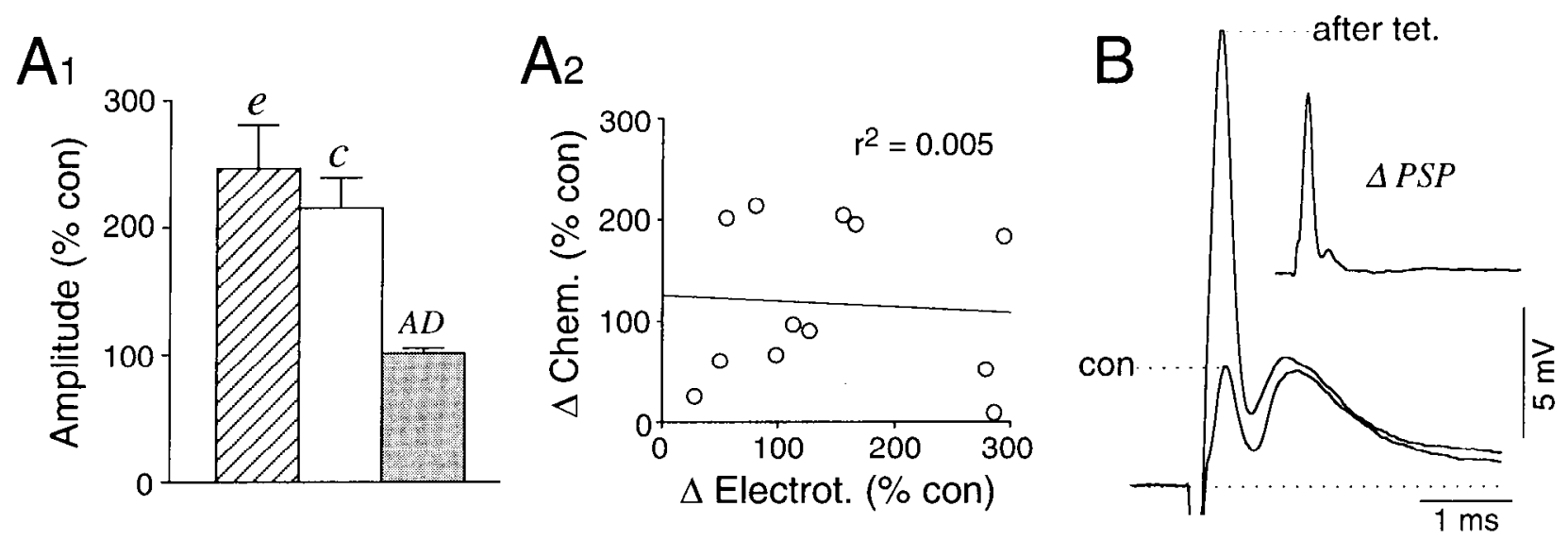

Figure 2. The two components of the mixed excitatory synaptic response are modified independently by afferent activity. Al, Bar plots represent the averaged amplitude of the electrotonic potential $(e)$, chemical EPSP $(c)$, and antidromic spike $(A D)$ expressed as percent of their control values, measured immediately after tetanic stimulation of the posterior eighth nerve (error bars represent SEM; $n=12$ ). Whereas both components of the synaptic response were affected dramatically, the antidromic spike amplitude (a measure of input conductance of the $\mathrm{M}$ cell) did not change significantly. $A 2$, Plot of the peak percent change (measured immediately after tetanic stimulation) in the chemical EPSP $(\Delta$ Chem.) versus that of the coupling potential $(\Delta$ Electrot.) for each of those 12 experiments. The two potentiations are uncorrelated $\left(r^{2}=0.005\right)$. B Tetanic stimulation can affect electrotonic coupling exclusively. Superimposed average responses $(n=12)$ obtained in control and after tetanic stimulation that restored electrotonic coupling (spontaneously reduced in this experiment) to its typical amplitude ( -3 times the amplitude of the chemical EPSP). The inset is the digitally subtracted difference between the two records $(\triangle P S P)$, which shows that the enhancement of electrotonic coupling occurred while there was minimal change in chemical transmission. Calibrations do not pertain to the inset.

tetanic stimulation (short trains of 4 pulses at $500 \mathrm{~Hz}$ applied at $2 \mathrm{sec}$ intervals during $4 \mathrm{~min}$, unless specifically testing the effects of tetanus duration), a suprathreshold stimulus strength was used that was sufficient to activate the $\mathbf{M}$ cell orthodromically at least once during each train (Yang et al., 1990). This paradigm was used to produce long-term potentiation (LTP) of both synaptic responses in an earlier study that was not concerned with the initial effects of the tetanus. In addition, the axon of the $\mathrm{M}$ cell was routinely activated by an electrode in the spinal cord (Fig. $1 A$ ) and, because the soma-dendritic membrane of this neuron does not support active electrogenesis (Faber and Korn, 1978), the antidronic spike amplitude was used as an indicator of the input conductance. The intradendritic membrane potential was in the range of -75 to $-88 \mathrm{mV}$ and remained stable throughout the duration of each experiment. All responses were measured, from prestimulation baseline to peak (see Pereda et al., 1994), after averaging sets of 10 or more consecutive traces. Student's $t$ test was used to assess statistical significance of the obtained data.

\section{RESULTS}

\section{Both components of the synaptic response exhibit activity-dependent short-term plasticity}

The initial effect of high-frequency stimulation on the amplitude of both components of the eighth nerve-evoked mixed synaptic response was explored (Fig. 1). The stimulation paradigm consisted of short trains of 4 pulses at $500 \mathrm{~Hz}$ applied at $2 \mathrm{sec}$ intervals for 4 min. At most, one cycle (2 sec) was missed before reverling to the test stimulus, in contrast to the earliest study, which was concerned with response modifications starting at 2-5 min after the end of the tetanization (Yang et al., 1990). This discontinuous stimulation paradigm produced short-lasting increases in the amplitudes of both components of the synaptic response (Fig. $1 C 1, C 2$ ), typically followed by a return to control levels in -3 min. In some cases, however, the potentiations decayed more slowly and gradually disappeared over $\sim 15 \mathrm{~min}$ (range 2 to $15 \mathrm{~min} ; n=$ 12). Figure $2 A 1$ summarizes the observed changes, which averaged $246.2 \pm 32.8 \%( \pm$ SEM) for the electrotonic coupling and $214 \pm 24.8 \%$ for the chemical EPSP of its control values (measured immediately after high-frequency stimulation). As illustrated in Figure $1 C 3$, the potentiated amplitudes of the electrotonic coupling potential and the chemical EPSP typically decayed in parallel. That is, as the two responses returned to their control values, the EPSP remained a constant fraction of the coupling potential, which suggests that a single mechanism underlies both effects. One possibility is a decrease in the membrane conductance of the $\mathrm{M}$ cell or, alternatively, there may be simultaneous modifications of both components by a common intracellular mechanism. The first possibility was rulcd out because the antidromic spike height of the $\mathrm{M}$ cell (measured immediately after tetanic stimulation), a measure of the input resistance of this neuron, averaged $101.4 \pm 3.8 \%$ of control (Fig. 2Al). Furthermore, the two modalities of transmission were modified simultaneously but separately, because in individual experiments the two components were not increased by the same percentage. Specifically, as illustrated in Figure $2 A 2$, there was no quantitative correlation between the initial potentiation of the two components $\left(r^{2}=0.005\right)$.

The fact that both modalities of synaptic transmission are modified separately by afferent activity was more evident in a set of experiments in which the amplitude of the electrotonic component was found to be reduced spontaneously during control conditions $(n=5)$, thereby reducing the typical 3:1 ratio between the size of the coupling potential and that of the chemical EPSP to $\sim 1: 1$ (compare Figs. $1 B, C 1$ and $2 B, c o n$ ). This reduction could not be related to a deterioration of the recording conditions because the chemical EPSP, the membrane potential of the M cell, and the antidromic spike remained at normal values. The magnitude of this spontaneous decoupling was variable and could be either partial, as with the experiment of Figure $2 B$, or effectively absolute (Fig. 3). Under this condition of diminished coupling, tetanic stimulation of the posterior eighth nerve was able to transiently restore and potentiate electrotonic coupling, which averaged $1156 \pm 315 \%$ of the control value. For the same experiments, the chemical EPSP increased to $177.9 \pm 32.2 \%$ of control, and the effects of tetanization on each component were significantly different $(p \leq 0.025)$. Furthermore, as also illustrated in Figure $2 B$, the activity-induced potentiation of electrotonic coupling could be observed in the absence of any detectable effect on chemical transmission. This distinction is observed best with the 

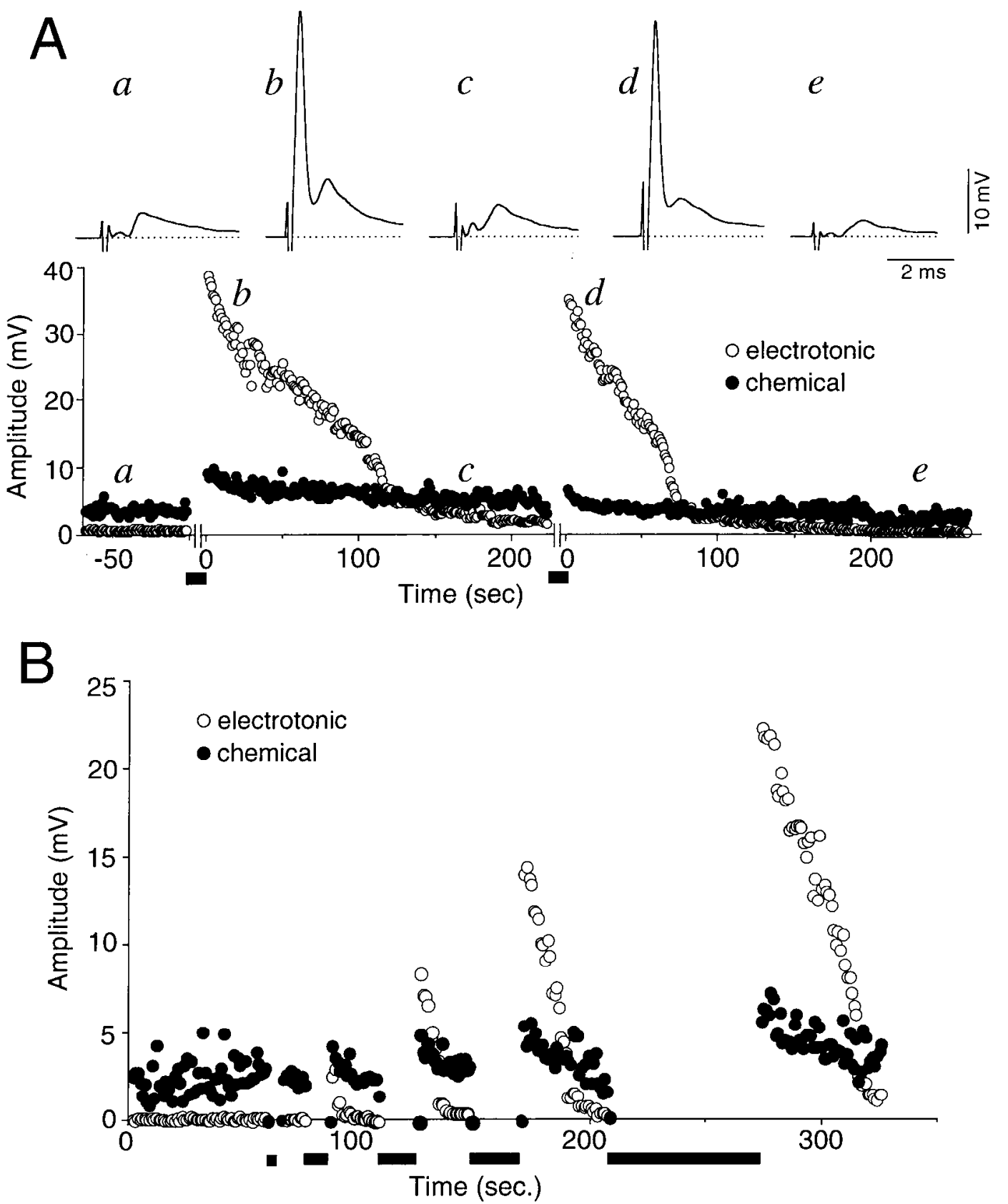

Figure 3. Tetanic stimulation transiently restores electrotonic coupling in spontaneously decoupled afferents. $A$, In this experiment, the spontaneous decoupling was nearly absolute, and the tetanic paradigm repeatedly restored coupling transiently and evoked STP of chemical transmission. Bottom, Plots of the amplitudes of the electrotonic $(O)$ and chemical $(-)$ components of the synaptic response versus time, encompassing the effects of two conditioning periods. Top, Representative averaged records $(n \geq 12)$ obtained at the times marked by the same lower case letters as at bottom. $B$, Discontinuous tetanic stimulation potentiates both electrotonic coupling and the chemical F.PSP in successive conditioning periods, the duration (length of the horizontal bars below the abscissa) of the tetanus and, hence, the number of bursts $(5,10,15,20$, and 40$)$ of nerve stimuli was increased progressively. Plots of the amplitudes of the electrotonic $(O)$ and chemical $(\bullet)$ components of the synaptic responses are against time. Note that both the magnitude and duration of the potentiations were increased in parallel with the number of bursts used.

difference waveform calculated by subtracting the control response from that recorded after high-frequency stimulation (Fig. $2 B, \triangle P S P$ ). This phenomenon is better illustrated in the experiment of Figure $3 A$, in which the degree of decoupling was nearly complete. In that situation, tetanic stimulation produced, along with a potentiation of the chemical EPSP, a dramatic restoration of electrotonic coupling that decayed rapidly over 1 to $2 \mathrm{~min}$, and these enhancements could be induced repeatedly.

The induction and magnitude of the short-term potentiations
(STPS) of both components depend on the characteristics of the stimulating paradigm, as illustrated in Figure $3 B$. In this experiment decoupling occurred spontaneously (same example as in Fig. $3 A$ ), and we examined the effect of the number of pulses necessary to evoke a transient recoupling of the eighth-nerve afferents. The induction, magnitude, and duration of the potentiation of both components of the synaptic response were all correlated with the number of bursts of stimuli used. For example, five bursts were ineffective, a train of 10 bursts produced very weak recoupling for 

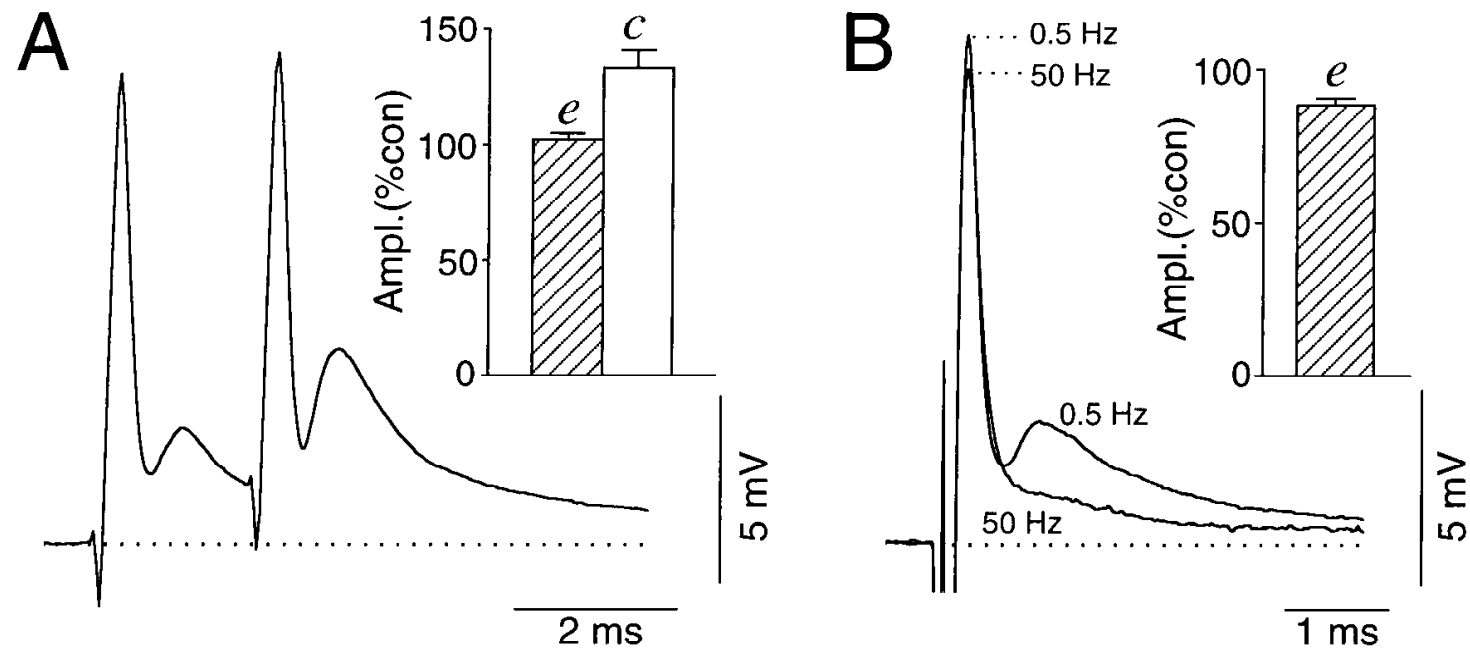

Figure 4. Comparison of effects of different stimulating paradigms on the amplitudes of both the electrotonic and the chemically mediated PSPs. A, Paired-pulse stimulation of the eighth nerve produces a pronounced facilitation of chemical transmission but minimally affects electrotonic coupling, as shown by the average of 25 responses. Inset, Bar plots represent the percent changes in amplitude of the second electrotonic coupling potential and the chemical EPSP compared with the first responses (\%con) for 16 experiments (error bars represent SEM). Chemical transmission was increased by 33.1\%, whereas the change in electrotonic coupling was insignificant $(2.3 \%)$ and the difference between the two components was highly significant $(p<0.008)$ $B$, Effect of continuous tetanic stimulation on both components of the synaptic response. Superimposed recordings represent an average of 12 consecutive traces obtained at two different stimulating frequencies, 0.5 and $50 \mathrm{~Hz}$. During high-frequency stimulation $(50 \mathrm{~Hz}$ ), the chemical component fatigued, whereas the electrotonic PSP remained almost the same. Inset, Bar plot representing the amplitude of the coupling potential during high-frequency stimulation, expressed as a percentage of the values obtained at $0.5 \mathrm{~Hz}$ (error bars signify SEM; $n=7$ ). Typically, the response decreased slightly in amplitude (by $11.5 \%$ in the average) possibly due to partial refractoriness of the afferents.

$5 \mathrm{sec}$, and a train of 40 bursts raised the coupling potential to 20 $\mathrm{mV}$, albeit transiently (Fig. $3 B$ ).

Overall, potentiations were found in 29 of 35 experiments; they were short-lasting in 17 cases, as described above, whereas in 12 other cases there were long-term increases in the amplitudes of both the electrotonic coupling and the chemical EPSP (Fig. 1B) that lasted for the duration of the recording period (up to $90 \mathrm{~min}$ ) (see also Yang et al., 1990). The potentiated responses averaged $201.8+26.6 \%$ of control for the electrotonic coupling and 205.4 $\pm 26.1 \%$ for the chemical EPSP. In that series, the antidromic spike of the $\mathrm{M}$ cell again was unchanged (mean $102.6 \pm 3.6 \%$ of control; $p>0.4$ ), indicating that the modification in junctional transmission occurred in the absence of any detectable effect on dendritic membrane conductance. It is not clear why the same tetanization paradigm produces STP in $-50 \%$ of the trials and LTP in the others. However, in a recent study we found that increasing the number of stimuli per tetanus from 4 to 6 or 8 increases the incidence of LTP to $\sim 90 \%$ (S. Kumar, A. Pereda, and D. Faber, unpublished data). That is, the persistence of the potentiations or its conversion to a nondecremental form may be related to the effective strength of the conditioning stimulation.

In summary, both junctional conductance and chemical transmission are modified, seemingly in parallel, by repeated brief tetani, possibly via a common intracellular mechanism. In the following sections, we will refer to these phenomena as STPs.

\section{Is STP of junctional conductance attributable to a presynaptic residual calcium mechanism?}

The transient potentiations of both components resemble the short-term changes in transmitter release at chemical synapses that are caused by activity-dependent transient increases in the concentration of calcium in the presynaptic terminal (Magleby, 1987; Zucker, 1989). We investigated whether paired-pulse stimulation, a paradigm known to increase presynaptic calcium, could produce STP of both electrotonic and chemical components. Paired stimulating pulses are known to produce a strong facilitation of the chemical EPSP at these synapses (Lin and Faber, 1988b). However, we found that although this stimulating paradigm typically produced an increase in chemical transmission, there was little or no change in electrotonic coupling (Fig. 4A). Bar graphs in Figure $4 A$ (inset) summarize the data obtained from 14 experiments; the chemical component of the EPSP evoked by the second pulse was found to be increased to $133.1 \pm 7.8 \%$ of the first EPSP. In contrast, the electrotonic coupling potential did not change, averaging $102.3 \pm 2.6 \%$ of its control value $(p>0.05)$. This finding was observed more clearly in those experiments in which several pulses (4-6) were used instead (Fig. 5B); whereas the chemical component became increasingly facilitated with successive pulses, the amplitude of the electrotonic component remained unchanged.

One possible explanation for the lack of effect of paired-pulse stimulations on coupling is that to trigger the observed changes in the junctional conductance, higher concentrations of residual calcium are needed, such as those produced by a continuous train of stimulating pulses $(50-100 \mathrm{~Hz})$. Such a stimulating paradigm has been shown to raise presynaptic calcium substantially in experimental preparations in which a direct measurement of the ion's concentration is possible (Swandulla et al., 1991; Delaney and Tank, 1994). High-frequency continuous stimulation of the posterior eighth nerve $(50-100 \mathrm{~Hz})$ for $30-60 \mathrm{sec}$ produced a progressive decrease in and eventual blockade of chemical transmission, whereas the electrotonic component remained nearly unchanged (Fig. 4B). Typically, the latter was reduced slightly, and it averaged $88.5 \% \pm 1.6(n=7)$ of control, possibly because of partial refractoriness of the presynaptic axons (Fig. $4 B$, inset). After high-frequency continuous stimulation, both the electrical and the chemical components return to control values within 

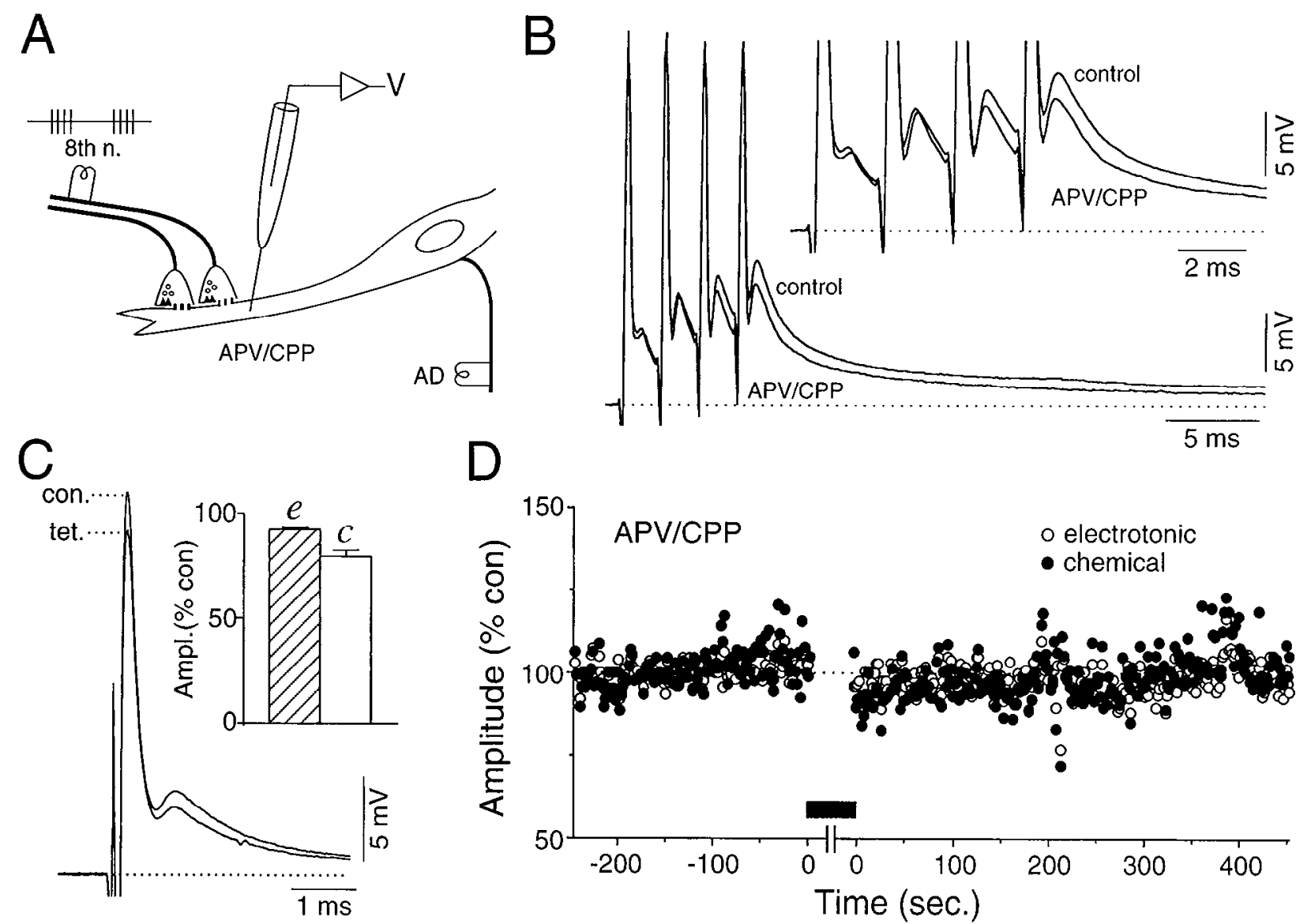

D

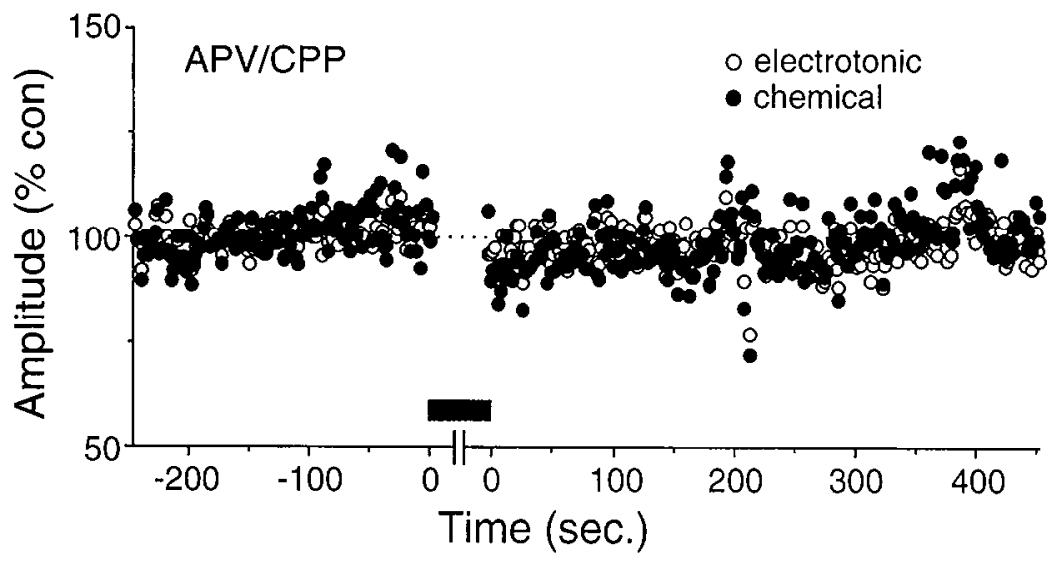

Figure 5. Induction of the STP of the synaptic responses depends on NMDA-receptor activation. $A$, Experimental arrangement, indicating that the brainstem of the fish was superfused continuously with a solution containing the NMDA-receptor blockers APV and CPP (50-100 $\mu$ M each) cither through the experiment or during test conditions. $B$, Superimposed synaptic responses evoked by a train of four eighth-nerve stimuli, in control and after superfusing with saline containing the antagonists (APV/CPP). Note that although the first chemical synaptic response produced by the train does not produce a significant NMDA receptor-mediated response, the late-facilitated components do. $C$, Effect of tetanic stimulation on the amplitude of both components of the synaptic response in the presence of NMDA-receptor blockers. Superimposed recordings represent the averages of the last 15 responses obtained before tetanic stimulation, and the first 15 after tetanic stimulation. Typically, the amplitudes of both components were slightly and transiently decreased. Inset, Bar diagrams summarizing the results of APV/CPP experiments, with the magnitude of the chemical (c) and clectrotonic $(e)$ responses expressed as percent of control values. Error bars denote SEM. $D$, Plot of the time course of one such experiment. The electrotonic coupling $(O)$ and the chemical EPSP $(\bullet)$ are expressed as percentages of their control values. In contrast with the experiments performed in the absence of NMDA blockers, the synaptic responses were decreased slightly immediately after tetanic stimulation.

seconds without potentiation of either component. These findings argue against a primary role for presynaptic calcium in the STP of coupling.

\section{The STPs of electrotonic coupling depend on both NMDA-receptor activation and postsynaptic calcium}

The lack of effect obtained with the continuous-stimulating paradigm led to the suggestion that operant glutamatergic chemical transmission, known to fatigue during continuous high-frequency stimulation, is critical for the induction of the plasticity in electrotonic transmission. Given that presynaptic bursts were effective in inducing STP of both components, we asked whether this stimulus paradigm would activate NMDA receptor-mediated responses at chemical synapses $(n=3)$. Activation of this glutamate-receptor subtype is known to promote modifications of synaptic efficacy (Malenka and Nicoll, 1993). Figure $5 B$ illustrates the synaptic responses evoked by a train of four eighth-nerve stimuli, in control and after superfusing with saline containing a mixture of the NMDA-receptor antagonists APV and CPP $(50 \mu \mathrm{M}$ each). The effect of the blockers depended on the number of pulses used. Whereas the first chemical synaptic response produced by the train did not produce a significant NMDA-receptor response, as indicated by the lack of blocker effect, the subsequent facilitated responses activated increasing amounts of this receptor. Note also that the slow tail of the EPSP is attenuated by the antagonists, indicating that after burst stimuli there is a longlasting activation of the NMDA receptor.

Next, we asked whether the repeated brief stimulation could evoke the transient potentiations in the presence of the NMDA blockers APV and CPP. Under this condition, tetanic stimulation failed to produce either STPs or LTPs of either component of the synaptic response. Rather, the tetanization was followed by transient depressions of both (Fig. $5 C$ ), to $92.4 \pm 1.1 \%$ of control for the electrotonic coupling potential and $79.3 \pm 3.2 \%$ for the chemical EPSP $(n=5)$. This result, summarized in Figure $5 \mathrm{C}(\mathrm{ba}$ plot in inset), was quantified by comparing the averages of the last 15 records before tetanic stimulation with the first 15 responses after the conditioning protocol. The time course of one of these experiments is illustrated in Figure $5 D$. 

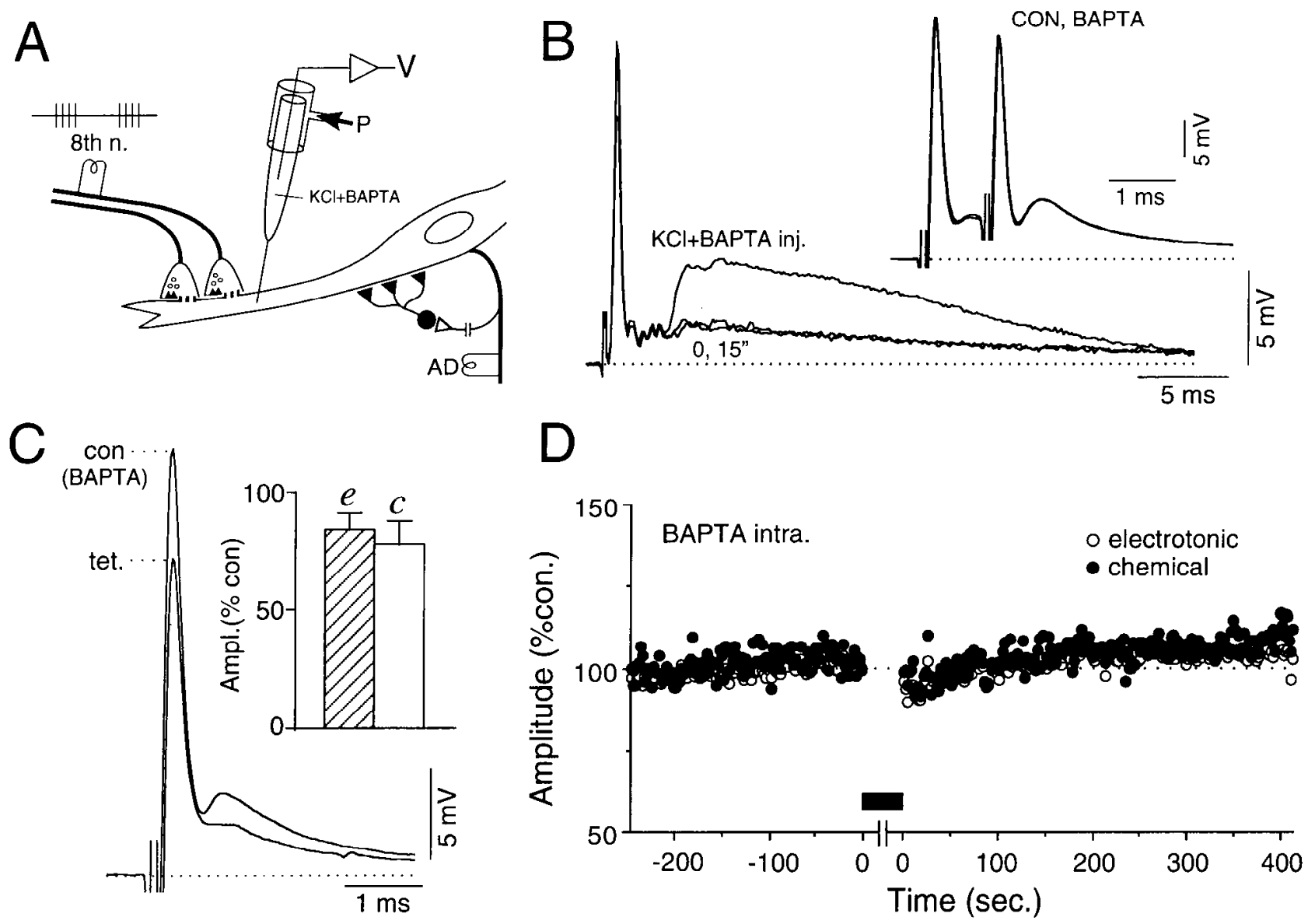

Figure 6. An elevation in postsynaptic calcium is necessary for the STP of the electrotonic coupling. $A$, Experimental arrangement. The same stimulating protocol was used after the calcium chelator BAPTA had been injected intradendritically through the recording electrode. $B$, Immediate effect of intradendritic pressure injection of the electrode solution $(2.5 \mathrm{~mm} \mathrm{KCl}, 10 \mathrm{~mm} \mathrm{HEPES}, 5 \mathrm{~mm}$ BAPTA, pH 7.2), as monitored by recordings of the antidromic action potential and recurrent inhibition evoked by spinal cord stimulation. As illustrated by the superimposed single traces, pressure injection produces a transient large appearance of a depolarizing recurrent IPSP, caused by a transient increase in the intracellular $\mathrm{Cl}$ concentration; this short-lasting depolarization was used as an indication of a successful pressure injection. Inset, BAPTA injection does not modify the paired-pulse facilitation seen with eighth-nerve stimulation. Superimposed traces represent the effect of paired stimulating pulses obtained at control (CON) and 10 min after the injection of BAPTA. $C$, Tetanic stimulation after intradendritic BAPTA injection reduces the amplitudes of both components of the synaptic response. Superimposed recordings represent the averages of the 15 responses obtained just before and after tetanic stimulation in one experiment. Inset, Bar diagrams depicting the mcan amplitudes of both components of the synaptic response, expressed as percentages of the control values, in five experiments in which the effects of tetanic simulation were examined in the presence of intracellular BAPTA. Error bars denote SEM. $D$, Graph illustrates the time course from one of the experiments. The size of the electrotonic coupling potential $(O)$ and the chemical EPSP $(\bullet)$, expressed as percentages of their control values. Both synaptic responses were decreased slightly just after tetanic stimulation. In this case, the depression was Iransient, although in others it was long-term.

These results suggested that the STPs require a postsynaptic increase in calcium concentration, because NMDA-receptor activation is known to cause an influx of this ion (Malenka and Nicoll, 1993). Therefore, the calcium chelator BAPTA was injected in the lateral dendrite of the $M$ cell in a attempt to block the appearance of the transient potentiations (Fig. 6A). The BAPTA was in a chloridecontaining solution, and successful injections (assuming that both BAPTA and chloride were distributed homogeneously in the solution) were signaled by large increases in the size of the collateral IPSP evoked by spinal cord stimulation (Fig. $6 \mathcal{A}$ ), caused by a shift in the chloride equilibrium potential to a more depolarized level. Whereas the injection of BAPTA did not modify paired-pulse facilitation (Fig. 6B), tetanic stimulation in this condition depressed both components of the synaptic response; a pronounced example is illustrated in Figure $6 C$. The magnitudes of these depressions were more pronounced than those obtained with the NMDA blockers, and their duration was either transient ( 2 cases) or long-lasting ( 3 cases). As summarized in Figure 6C (bar plots in inset), the coupling potential and the EPSP were reduced, on average, to $83.8 \pm 7.4$ and $78.1 \pm 9.8 \%$ of their control values, respectively $(n=5)$. Again, for this analysis an average of the last 15 traces before the tetanic stimulation was taken as the control and compared with an average of the first 15 traces after the tetanizing protocol. The time course of one of these experiments is illustrated in Figure $6 D$; in this case, the tetanic stimulation evoked, in the presence of intracellularly injected BAPTA, transient depressions of both the electrotonic potential and the chemical EPSP.

\section{DISCUSSION}

We show here that, in addition to a previously described LTP, electrotonic coupling between eighth-nerve afferent fibers and the lateral dendrite of the $M$ cell can be modified transiently by patterned afferent activity. Although it is well known that chemical transmission exhibits various forms of transient plasticity with 
decay times ranging from seconds to hours, fast and reversible activity-dependent changes in junctional conductance have not been described previously. The evidence is consistent with the idea that activity transiently potentiates the posterior eighth-nerve mixed synaptic response by acting separately on electrical and chemical transmission, because there could be differential effects on both forms of transmission. This distinction was most evident in those experiments in which spontaneous decoupling was observed in control conditions. These modifications were specific to the two modes of transmission, because no changes in the input conductance of the dendrite were observed. However, although both potentiations were triggered by a postsynaptic calcium influx, evidence that the magnitudes of the changes were uncorrelated reflects different efficacies of the regulatory processes, possibly at the level of the target proteins.

The reversible changes in cellular coupling depended on a particular type of intermittent or burst-like type of tetanic stimulation and were not produced by continuous high-frequency tetani. This type of stimulating paradigm, which is based on the functional characteristics and firing pattern of these auditory fibers (Fay, 1978), also can trigger an NMDA-dependent LTP of both components of the synaptic response (Yang et al., 1990). Pharmacological and immunohistochemical evidence has indicated that the neurotransmitter at these contacts is glutamate, and that both NMDA and non-NMDA receptors are present along the medial and lateral portion of the lateral dendrite of the $\mathrm{M}$ cell, where these fibers are segregated (Wolszon and Faber, 1987; Sur et al., 1994). Our present results indicate that this type of stimulating paradigm optimizes NMDA-receptor activation, in contrast to a continuous train of impulses that fatigues chemical transmission. Accordingly, as with the LTP of these synapses (Yang et al., 1990), the induction of the STPs was prevented by NMDAreceptor antagonists and by postsynaptic injections of the calcium chelator BAPTA. Indeed, recent evidence from mammalian hippocampus also indicates that NMDA-receptor activation may not always lead to induction of LTP, but also may elicit a variety of different forms of synaptic plasticity, including STP and long-term depression (Malenka and Nicoll, 1993). In particular, the STPs that we report here share many similarities with that reported in the hippocampus, including time course, and dependence on NMDA-receptor activation and postsynaptic calcium increase (Malenka, 1991; Hanse and Gustafsson, 1992). Of interest, the same stimulating paradigm can trigger either STP or LTP. Because both phenomena require NMDA-receptor activation and an increase in postsynaptic calcium for their induction, the two forms of plasticity presumably are closely related, and stabilization of the potentiation may require the activation of a switch-like mechanism, perhaps involving the threshold activation of some biochemical processes.

Whereas tetanic stimulation during NMDA-receptor blockade evoked a transient depression of both components of the synaptic response (possibly attributable to partial refractoriness of some of the fibers), a more prominent and long-lasting depression was observed in some of the experinents in which BAPTA was injected intradendritically. A possible explanation for this result is that in these latter cases the BAPTA concentration was insufficient to chelate all of the incoming calcium, an interpretation that is consistent with current views in which smaller rises in calcium can evoke long-term depression (Malenka and Nicoll, 1993). An alternative hypothesis would be that LTP and long-term depression are triggered simultaneously but that the induction of depression is calcium-independent.
In contrast, whereas postsynaptic elevations of calcium caused an enhancement of both components of the synaptic response, no changes in junctional conductance were detected after stimulating paradigms known to raise the presynaptic calcium concentration. Pairs or short trains of presynaptic stimuli strongly facilitated the chemical response without significantly affecting electrotonic coupling. Paired-pulse facilitation is generally believed to be attributable to an activity-dependent, transient increase in the presynaptic concentration of calcium, which causes a short-lasting enhancement of transmitter release (Stanley, 1986; Zucker, 1989). The lack of effect on coupling cannot be related simply to a higher calcium requirement of gap junction channels because continuous tetanic stimulation at $50-100 \mathrm{~Hz}$, shown to increase presynaptic calcium levels progressively in other preparations (Swandulla et al., 1991; Delancy and Tank, 1994), also failed to enhance electrical coupling. Additional support for the conclusion that changes in presynaptic calcium do not alter coupling comes from a previous study reporting that although spike broadening produced by injecting 4-aminopyridine in these afferents (a manipulation that increases the presynaptic calcium concentration evoked by a single-nerve impulse) could enhance or unmask the chemically mediated EPSP, it had no effect on the amplitude of the electrotonic potential (see Fig. 11 in Lin and Faber, 1988b).

An increase in free cytoplasmic calcium can reduce junctional conductance directly (Baux et al., 1978). However, the necessary concentration is high (high micromolar to millimolar range; see Bennett and Spray, 1987) compared with that involved in functions such as secretion or muscle contraction, and it is unlikely that this effect represents a normal physiological mechanism. We suggest that in this case calcium is acting as a messenger molecule. The fact that the STP was induced only postsynaptically, even though calcium can diffuse from one side to the other through the gap junctions (small molecular weight dyes can diffuse across these gap junctions; Pereda et al., 1995) suggests that the calciumdependent mechanism is located close to the NMDA-receptor complex in the postsynaptic area (Fig. 7). Consistent with this idea, gap-junction plaques, which are located at the center of a contact zone of the terminal, are close to and surrounded by the chemical synapses found at the periphery of the terminal (Tuttle et al., 1986). The fast onset and transient characteristics of these potentiations suggest that calcium triggers post-translational modification of proteins, such as phosphorylation. Both glutamate receptors and connexins, the family of proteins that form gap junctions channels (Bennett et al., 1991), are good substrates for phosphorylation (Saéz et al., 1990, 1993; Blackstone et al., 1994) by calcium-activated kinases. The activation of one such enzyme, protein kinase $\mathrm{C}$, did not enhance any of the components of the eighth-nerve responses in the $\mathrm{M}$ cell (Silva et al., 1995). An alternative candidate is calcium/calmodulin-dependent protein kinase II (CaMKII), which is believed to play an important role in hippocampal LTP (Lisman, 1993). CaMKII has been reported to be highly enriched in postsynaptic densities (Kennedy et al., 1983; Kennedy, 1995), and it can be activated rapidly (Murphy et al., 1994). It promotes phosphorylation of glutamate GluR1 receptor in vitro and enhances kainate-gated currents in cultured hippocampal neurons (McGlade-McCulloch et al., 1993). In addition, it promotes phosphorylation of liver connexin-32 (Saéz et al., 1990), one of the 16-member family of connexins, although it is not known yet whether it also can promote phosphorylation of connexin-43, the putative connexin candidate at these nerve endings (Yox et al., 1990). Finally, the fact that this fast change in junctional conductance occurs only when postsynaptic calcium is 


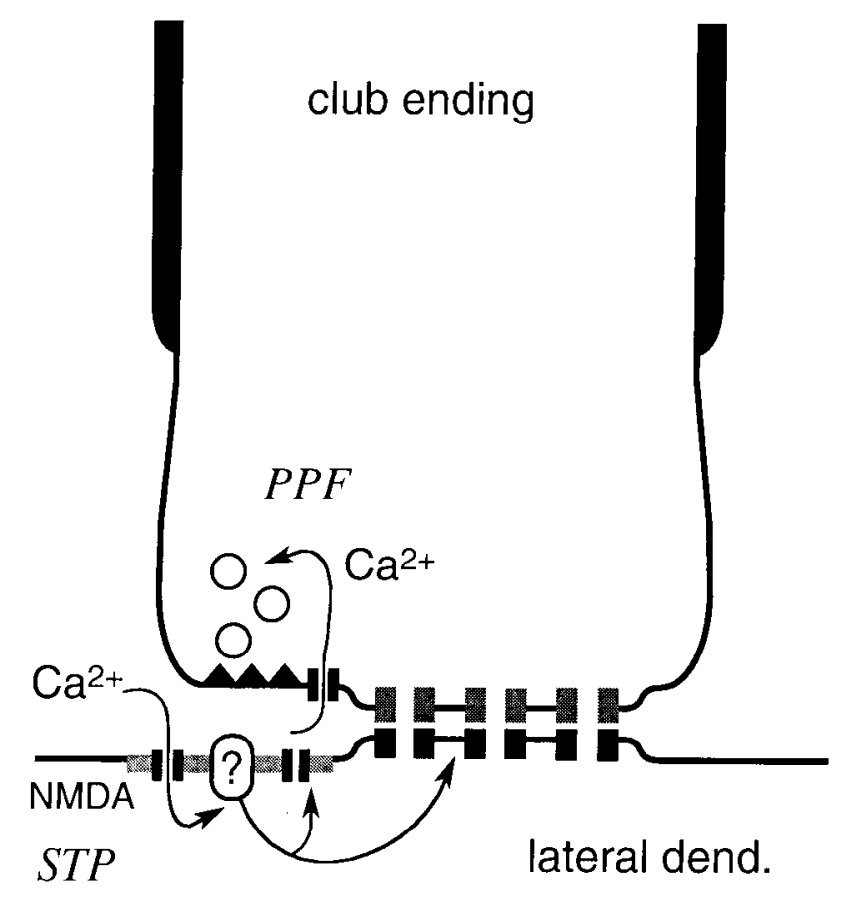

Figure 7. Schematic representation of the proposed mechanisms for affecting the strength of the eighth-nerve input. During paired-pulse stimulation (paircd-pulsc facilitation, $P P F$ ) an incrcasc in presynaptic calcium increases transmitter release without affecting junctional conductance. Discontinuous tetanic stimulation, by activating NMDA receptors, instead promotes an elevation in postsynaptic calcium concentration which, in turn, activates an unknown intracellular calcium sensor (?), which we speculate should be located in the proximity of the NMDA receptor, causing an enhancement of both components of the synaptic response (STP).

elevated suggests that the two sides of the gap junction plaque can be modulated independently. This speculation is supported by previous results obtained by intradendritic injections of the catalytic subunit of the cAMP-dependent protein kinase, which suggested that an increase in junctional conductance can be obtained by modifying the channels at the dendritic side ( $M$ cell) of the junctional plaque alone (Pereda et al., 1994).

From a functional perspective, an NMDA-mediated enhancement of electrotonic coupling not only contributes to an enhanced evoked depolarization of the lateral dendrite of the $M$ cell through both modes of transmission, but it also may provide a mechanism for increasing synchronization of a population of afferents. Specifically, these endings are effectively coupled to each other through the lateral dendrite, such that enhanced electrical coupling might facilitate presynaptic firing and, thereby, modify the input-output relationship of eighth-nerve afferents (Pereda et al., 1995).

The NMDA receptor-mediated modulation of electrical coupling described in this study may represent a more general property that could play an important physiological role in other systems in which the two modes of intercellular communication coexist as, for example, during development and in the adult mammalian hippocampus and neocortex (Monaghan and Cotman, 1985; Dudek et al., 1986; Goodman and Shatz, 1993). Indeed, electrical coupling and NMDA-receptor activitydependent plasticity both influence development (Goodman and Shatz, 1993; Kandler and Katz, 1995). This interaction also may have important pathological implications because both NMDA receptors and gap junctions have been implicated in epileptogen- esis (Dudek et al., 1986; Meldrum, 1994). The function of the NMDA receptor is enhanced in the hippocampus of kindled rats, and its antagonists are potent anticonvulsants (Meldrum, 1994). Electrical coupling was found to be increased in an experimental model of epilepsy and, moreover, the seizure-like activity was suppressed under conditions that reduce gap-junctional conductance (Perez-Velazquez et al., 1994). Thus, NMDA-induced modulation of electrical coupling might contribute substantially to the epileptogenic properties of this glutamate-receptor subtype.

The results presented here support the view that cellular coupling through gap-junction channels is a dynamic feature of interneuronal communication and that, strikingly, it can be modulated transiently by cell activity. Finally, these results also support the idea that activation of NMDA receptors does not necessarily generate LTP but, instead, may trigger a repertoire of distinct forms of synaptic plasticity (Malenka and Nicoll, 1993).

\section{REFERENCES}

Bartelmez GW (1915) Mauthner's cell and the nucleus motorius tegmenti. J Comp Neurol 25:87-128.

Baux G, Simmoneau M, Tauc L, Segundo JP (1978) Uncoupling of electrotonic synapses by calcium. Proc Natl Acad Sci USA 75:4577-4581.

Bennett MVL (1977) Electrical transmission: a functional analysis and comparison with chemical transmission. In: Cellular biology of neurons, Vol 1, Sect 1, Handbook of physiology. The nervous system (Kandel ER, ed), pp 357-416. Baltimore: Williams \& Wilkins.

Bennett MVL, Spray DC (1987) Intercellular communication mediated by gap junctions can be controlled in many ways. In: Synaptic function (Edelman GM, Gall WE, Cowan WM, ed), pp 21-56. London: Wiley-Interscience.

Bennett MVL, Barrio LC, Bargiello TA, Spray DC, Hertzberg E, Saćz JC (1991) Gap junctions: new tools, new answers, new questions. Neuron 6:305-320.

Blackstone C, Murphy TH, Moss SJ, Baraban JM, Huganir RL (1994) Cyclic AMP and synaptic activity-dependent phosphorylation of AMPA-preferring glutamate receptors. J Neurosci 14:7585-7593.

Bodian D (1937) The structure of the vertebrate synapse: a study of the axon endings on Mauthner's cell and neighboring centers in the goldfish. J Comp Neurol 1:117-160.

Cepeda C, Walsh JP, Hull CD, Howard SG, Buchwald NA, Levine MS (1989) Dye-coupling in the neostriatum of the rat. I. Modulation by dopamine-depleting lesions. Synapse 4:229-237.

Delancy KR, Tank DW (1994) A quantitative measurcment of the dependence of short-term synaptic enhancement on presynaptic residual calcium. J Neurosci 14:5885-5902.

Dudek FE, Snow RW, Taylor C (1986) Role of electrical interactions in synchronization of epileptiform bursts. Adv Neurol 44:593-617.

Eaton RC, Di Domenico R, Nissanov J (1991) Role of the Mauthner cell in sensorimotor integration by the brain stem escape network. Brain Behav Evol 37:272-285.

Faber DS, Korn H (1978) Electrophysiology of the Mauthner cell: basic properties, synaptic mechanisms, and associated networks. In: Neurobiology of the Mauthner cell (Faber DS, Korn H, eds), pp 47-132. New York: Raven.

Fay RR (1978) Coding of information in single auditory-nerve fibers of the goldfish. J Acoust Soc Am 63:136-146.

Fukami Y, Furukawa T, Asada Y (1964) Excitability changes of the Mauthner cell during collateral inhibition. J Gen Physiol 48:581-600.

Furshpan EJ (1964) Electrical transmission at an excitatory synapse in a vertebrate brain. Science 144:878-880.

Goodman CS, Shatz CJ (1993) Developmental mechanisms that generate precise patterns of neuronal connectivity. Cell 72:427-437.

Hanse H, Gustafsson B (1992) Postsynaptic, but not presynaptic, activity controls the early time course of long-term potentiation in the dentate gyrus. J Neurosci 12:3226-3240.

Jessel TM, Kandel E (1993) Synaptic transmission: a bi-directional and self-modifiable form of cell-cell communication. Cell 72:1-30.

Johnson BR, Peck JH, Harris-Warrick RM (1993) Amine modulation of electrical coupling in the pyloric network of the lobster stomatogastric ganglion. J Comp Physiol [A] 172:715-732. 
Kandler K, Katz. I.R (1995) Neuronal coupling and uncoupling in the developing nervous system. Curr Opin Neurobiol 5:98-105.

Kennedy MB (1995) The postsynaptic density. Curr Opin Neurobiol 3:732 737 .

Kennedy MB, Bennett MK, Erondu NE (1983) Biochemical and immunohistochemical evidence that the "major postsynaptic density protein" is a subunit of a calnodulin-dependent protein kinase. Proc Natl Acad Sci USA 80:7357-7361.

Lin JW, Faber DS (1988a) Synaptic transmission mediated by single club endings on the goldfish Mauthner cell. I. Characteristics of electrotonic and chemical postsynaptic potentials. J Neurosci 8:1302-1312.

Lin JW, Faber DS (1988b) Synaptic transmission mediated by single club endings on the goldfish Mauthner cell. II. Plasticity of excitatory postsynaptic potentials. J Neurosci 8:1313-1325.

Lisman J (1993) The CaM kinase II hypothesis for the storage of synaptic memory. Trends Neurosci 17:406-412.

Magleby KL (1987) Short-term changes in synaptic efficacy. In: Synaptic function (Edelman GM, Gall WE, Cowan WM, eds), pp 21-56. London: Wiley-Interscience.

Malenka RC (1991) Postsynaptic factors control the duration of synaptic enhancement in area CA1 of the hippocampus. Neuron 6:305-320.

Malenka RC, Nicoll RA (1993) NMDA-receptor-dependent synaptic plasticity: multiple forms and mechanisms. Trends Neurosci $16: 521-527$.

McGlade-McCulloch E, Yamamoto H, Tan SE, Brickey DA, Soderling TA (1993) Phosphorylation and regulation of glutamate receptors by calcium/calmodulin-dependent protein-kinase II. Nature 362:640-642.

Meldrum BS (1994) The role of glutamate in epilepsy and other CNS disorders. Neurology 44[Suppl 8]:S14-S23.

Monaghan DT, Cotman CW (1985) Distribution of $N$-methyl-Daspartate-sensitive $\mathrm{L}-\left[{ }^{3} \mathrm{H}\right] \mathrm{glutamate}$-binding sites in rat brain. $\mathrm{J}$ Neurosci 5:2909-2919.

Murphy TH, Blatter LA, Bhat RV, Fiori RS, Wier G, Baraban JM (1994) Differential regulation of calcium calmodulin-dependent protein kinase II and p42 MAP kinase activity by symaptic Iramsmission. J Neurusci 14:1320-1331.

Nakajima Y (1974) Fine structure of the synaptic endings on the Mauthner cell of the goldfish. J Comp Neurol 156:375-40'2.

O'Donnell P, Grace AA (1993) Dopaminergic modulation of dye coupling between neurons in the core and shell regions of the nucleus accumbens. J Neurosci 13:3456-3471.

Peinado A, Yuste R, Katz L (1993) Extensive dye coupling between rat neocortical neurons during the perind of circuit formation. Neuron 10:103-114

Penn AA, Wong RO, Shatz CJ (1994) Neuronal coupling in the developing mammalian retina. J Neurosci 14:3805 3815.

Pereda A, Bell T, Faber DS (1995) Retrograde synaptic communication via gap junctions coupling auditory afferents to the Mauthner cell. J Neurosci 15:5943-5955.

Pereda A, Nairn A, Wolzson L, Faber DS (1994) Postsynaptic modulation of synaptic efficacy at mixed synapses on the Mauthner cell. J Neurosci 14:3704-3712.
Pereda A, Triller A, Korn H, Faber DS (1992) Dopamine enhances both electrotonic coupling and chemical excitatory postsynaptic potentials at mixed synapses. Proc Natl Acad Sci USA 89:12088-12092.

Perez-Velazquez JL, Valiante TA, Carlen PL (1994) Modulation of gap junctional mechanisms during calcium-free induced field burst activity: a possible role for electrotonic coupling in epileptogenesis. J Neurosci 14:4308-4317.

Piccolino M, Neyton J, Gerschenfeld H (1984) Decrease in gap junctional conductance induced by dopamine and cyclic adenosine $3^{\prime}, 5^{\prime}-$ monophosphate in horizontal cells of the turtle retina. J Neurosci $4: 2477-2488$

Saéz JC, Nairn AC, Czernik A, Spray DC, Hertzberg EL, Greengard P, Bennett MVL (1990) Phosphorylation of connexin 32, the hepatocyte gap junction protein, by cAMP-dependent protein kinase, protein kinase $\mathrm{C}$, and $\mathrm{Ca}^{2+} /$ calmodulin-dependent protein kinase 11 . Eur J Biochem 192:263-273.

Saéz JC, Berthoud VM, Moreno AP, Spray DC (1993) Gap junctions: multiplicity of controls in differentiated and undifferentiated cells and possible functional implications. In: Advances in second messenger and phosphoprotein research, Vol 27 (Shirish Shenolikar S, Nairn AC, eds), pp 163-198. New York: Raven.

Silva A, Kumar S, Pereda A, Faber DS (1995) Regulation of synaptic strength at mixed synapses: effects of dopamine receptor blockade and protein kinase $\mathrm{C}$ activation. Neuropharmacology, 34:1559-1565.

Stanley EF (1986) Decline in calcium cooperativity as the basis of facilitation at the squid giant synapse. J Neurosci 6:782-789.

Swandulla D, Hans M, Zipser K, Augustine GJ (1991) Role of residual calcium in synaptic depression and post-tetanic potentiation: fast and slow calcium signaling in nerve terminals. Neuron 7:915-926.

Sur C, Wenthold R, Triller A (1994) Differential cellular distribution of excitatory amino acid receptor subunits on the M-cell of teleost. Soc Neurosci Abstr 20:489.

Teranishi T, Neighs K, Kato S (1983) Dopamine modulates S-potential amplitude and dye-coupling between external horizontal cells in carp retina. Nature 301:243-286.

Tuttle R, Masuko S, Nakajima Y (1986) Freeze fracture study of the large myelinated club ending synapse on the goldfish Mauthner cell: special reference to the quantitative analysis of gap junctions. J Comp Neurol 246:202-211.

Wolszon L, Faber DS (1988) Fast EPSPs evoked in the Mauthner cell by sensory afferents are due to NMDA receptor activation. Soc Neurosci Abstr 14:939.

Yang XD, Faber DS (1991) Initial synaptic efficacy influences induction and expression of long-term changes in transmission. Proc Natl Acad Sci USA 88:4299-4303.

Yang XD, Korn H, Faber DS (1990) Long-term potentiation of electrotonic coupling at mixed synapses. Nature $348: 542-545$.

Yox DP, Faber DS, Nicholson BJ (1990) Gap-junction antibody attenuates electrical coupling between the goldfish Mauthner (M-) cell and its eighth nerve afferents. Soc Neurosci Abstr 16:185.

Zucker RS (1989) Short-term synaptic plasticity. Ann Rev Neurosci 12: 13-31. 